ISSN 2349-9368 (Online); EAPJMER/issn. 2349-9368/2016; Volume 4 Issue 2 (2018)

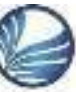

ELK

Asia Pacific Journals

www.elkjournals.com

\title{
PROCESS PARAMETER OPTIMIZATION FOR STEEL RECYCLING PROCESS BY PARTICLE SWARM OPTIMIZATION (PSO) ALGORITHM
}

\begin{tabular}{|c|c|c|}
\hline ALLURKAR & DR. MITNALA & DR. K. L. \\
BASWARAJ.S & SREENIVASA RAO & NARASIMHAMU \\
Research Scholar, & Professor, Mechanical & Professor, Department of \\
Mechanical Engineering & Engineering Department, & Mechanical Engineering, Sree \\
Department, JNT & JNTU CEH, Kukatpally, & Vidyanikethan Engineering \\
University, Kukatpally, & Hyderabad (Telangana State), & College, A.Rangampet, \\
Hyderabad, (Telangana & India & Tirupati, (Andhrapradesh), \\
State), India, & $\underline{\text { raoms63@yahoo.com }}$ & India, \\
allurkar@gmail.com & & klsimha@gmail.com \\
\hline
\end{tabular}

\begin{abstract}
In this paper optimization of parameters for recycling of steel process by using Particle Swarm Optimization (PSO) algorithm was used. For analysis five significant affecting input process parameters were considered with three objective functions. The material selected for experimentation was steel rod of diameter $16 \mathrm{~mm}$ manufactured by secondary steel manufacturing process. The three objective functions were maximization of Tensile strength (N/mm2), Hardness number value (No.) and minimization of Energy consumption $(\mathrm{Kw}-\mathrm{H})$. By Taguchi's design of experiment optimal combination of 46 input parameters at various levels were generated and experiments are conducted and responses were noted for each corresponding level. Mathematical model for the given problem was formed and Regression equation was generated by using Response Surface Methodology. PSO, a modern heuristic algorithm was used to solve the regression equation. The optimum results obtained by applying above algorithm were tested experimentally and results were compared. Significant improvement was observed in the objective function and the same was presented in a systematic manner.
\end{abstract}

Abstract

Keywords: global, population, pso,steel, recycling.

\section{INTRODUCTION}

Steel is used as a main material in many engineering fields. There is a significant difference in tensile strength and hardness number values from one manufacturer to another. Hence in this paper modern optimization technique called as particle swarm optimization algorithm is used to enhance the objective function along with 
ISSN 2349-9368 (Online); EAPJMER/issn. 2349-9368/2016; Volume 4 Issue 2 (2018)

minimum energy consumption per ton of steel. From the available literature this gap was observed and the same has been addressed to meet the desired goal.

\section{PROCESS PARAMETERS}

It is observed that there was a significant variation in tensile strength and hardness number values for different secondary steel manufacturers. Based on literature and consultation with experts from secondary steel manufacturing industries five significant affecting input process parameters were identified with their levels. They were Furnace temperature $\left(\mathrm{Ft}\right.$ in $\left.{ }^{\circ} \mathrm{C}\right)$ ), Sponge steel addition (SS in \%), Scrap steel composition (SCS in \%), TDS number of water used (TDS in No.) and Quenching temperature of steel $\left(\mathrm{Qw}\right.$ in $\left.\left.{ }^{\circ} \mathrm{C}\right)\right)$. Input parameters with their levels were shown in Table.1. For analysis of objective function, steel rod (diameter $16 \mathrm{~mm}$ ) of 2 feet length was used on universal testing machine (UTM), and for hardness number value steel rod of $1 \mathrm{~cm}$ length with its flat face polished with emery paper of different grades was used on Brinell hardness testing machine. The process parameters involved are interdependent and the entire process of secondary steel making is complex. Only prime influencing parameters are considered for analysis starting scrap sorting to storing of final steel bars at the store yard. Minutely the process is observed, weaknesses are identified and the same is incorporated in the process. The main objective functions are to maximize tensile strength and hardness number value with minimum consumption of energy in the entire process. The input parameters with their levels are shown in Ref Table.1 below.

\section{MODEL FORMULATION}

The optimization model for the given steel recycling problem is formulated as shown below in equation (1).

$$
\text { Find } \mathrm{X}\left[\begin{array}{c}
F t \\
S S \\
S C S \\
T D S \\
Q W
\end{array}\right]
$$

Max. T.S $=-12105+13.37 \mathrm{Ft}+82.0 \mathrm{SS}-$ 3.2 SCS+ 8.7 TDS+1.72 Qw- $0.00377 \mathrm{Ft}^{*}$

Ft-

$$
0.017 \mathrm{SS} * \text { SS- }
$$

0.0042 SCS*SCS-0.0142 TDS*TDS$0.00137 \mathrm{Qw}^{*} \mathrm{Qw}-$ 
ISSN 2349-9368 (Online); EAPJMER/issn. 2349-9368/2016; Volume 4 Issue 2 (2018)

$0.0400 \mathrm{Ft} * \mathrm{SS}+0.0060 \mathrm{Ft} * \mathrm{SCS}-$

$0.0020 \mathrm{Ft}^{*} \mathrm{TDS}+0.00000 \mathrm{Ft}^{*} \mathrm{Qw}-$

$0.280 \mathrm{SS} * \mathrm{SCS}+0.100 \mathrm{SS} * \mathrm{TDS}+0.0160 \mathrm{~S}$

S*Qw-0.0200 SCS*TDS-

$$
0.0040 \mathrm{SCS} * \mathrm{Qw}-
$$

$0.0080 \mathrm{TDS}^{*} \mathrm{Qw} \geq 580$

Such That

Hardness number value must be high and Energy consumption rate should be low and corresponding regression equations were used.

\section{METHOD: PARTICLE SWARM} OPTIMIZATION (PSO) ALGORITHM

Particle swarm optimization method was proposed for the first time by Dr. Kennedy and Dr. Eberhart in 1995. It was a nature inspired modern heuristic technique used for solving optimization problems in manufacturing industries will less computational complexity. The main characteristic of Particle Swarm Optimization is, it is best suitable for multi objective optimization function, easy to implement and converges quickly when compared to other modern optimization techniques. It conducts search using a population (swarm) of individuals (particles) that are updated with each iteration. Each particle in the swarm is described by position and velocity. It helps to find the particle best position that results in the best evaluation of a given fitness function.

\subsection{Algorithm Process for Particle Swarm Optimization with sample calculation}

The main objective was to maximize tensile strength and hardness number with minimum consumption of energy. The objective function is solved by using particle swarm optimization algorithm. The algorithm flow with sample calculation is represented below:

Input:

Number of particles in population $($ population size $)=5$,

Number of iterations $=1$.

Step 1. Generate initial population.

Initial population = $\left[\begin{array}{lllll}1675 & 15 & 80 & 40 & 525 \\ 1675 & 12.5 & 75 & 30 & 500 \\ 1700 & 15 & 80 & 30 & 525 \\ 1675 & 12.5 & 80 & 35 & 550 \\ 1675 & 15 & 85 & 35 & 500\end{array}\right]$,

Step 2. Find fitness values (Tensile Strength) of all particles. 
ISSN 2349-9368 (Online); EAPJMER/issn. 2349-9368/2016; Volume 4 Issue 2 (2018)

$$
\text { Tensile Strength }=\left[\begin{array}{l}
621.5125 \\
612.7325 \\
632.6088 \\
607.6875 \\
618.9788
\end{array}\right]
$$

Step 3. Generate initial velocity (Old velocity) matrix randomly which has size same as

population.

Initial
$\left[\begin{array}{rrrrrr}3.2261 & 0.8329 & 3.4097 & -3.0644 & -1.2736 \\ -3.7062 & 0.3070 & 1.8979 & -2.5502 & -0.5900 \\ -3.2147 & -1.5742 & 2.2410 & 0.2957 & 2.1526 \\ 1.1115 & 3.1452 & -3.5145 & -2.5938 & -0.6693 \\ 1.9183 & 3.1436 & -3.7932 & -2.8995 & -0.6073\end{array}\right]$

Step 4. Assigning the particle best and global best.

Assign each particle to its $\mathrm{P}$ best. Assign particle with maximum throughput to $\mathrm{G}$ best. Particle best =

$\left[\begin{array}{lllll}1675 & 15 & 80 & 40 & 525 \\ 1675 & 12.5 & 75 & 30 & 500 \\ 1700 & 15 & 80 & 30 & 525 \\ 1675 & 12.5 & 80 & 35 & 550 \\ 1675 & 15 & 85 & 35 & 500\end{array}\right]$

Fitness $=\left[\begin{array}{l}621.5125 \\ 612.7325 \\ 632.6088 \\ 607.6875 \\ 618.9788\end{array}\right]$

Global best $=\left[\begin{array}{lllll}1700 & 15 & 80 & 30 & 525\end{array}\right]$,

Fitness of Global best $=632.6088$

Step 5. Calculate new velocity for each particle i by using equation (2)

$$
\begin{gathered}
V_{\text {inew }}=\omega * V_{i}+C_{p} * \operatorname{rand}(0,1) *\left(P_{\text {best }}-X_{i}\right)+C_{g} * \operatorname{rand}(0,1) *\left(G_{\text {best }}-X_{i}\right) \\
\text { (2) New }
\end{gathered}
$$

velocity $=$

$$
\left[\begin{array}{rrrrr}
3.1910 & 0.1666 & 0.6819 & -4.0000 & -0.2547 \\
2.0636 & 3.4877 & 3.6969 & -0.5100 & 4.0000 \\
-0.6429 & -0.3148 & 0.4482 & 0.0591 & 0.4305 \\
4.0000 & 4.0000 & -0.7029 & -4.0000 & -4.0000 \\
4.0000 & 0.6287 & -4.0000 & -4.0000 & 4.0000
\end{array}\right]
$$

Step 6. Prepare new population as follows.

New
$\left[\begin{array}{llllll}1675 & 15 & 80 & 40 & 525 \\ 1700 & 15 & 80 & 30 & 525 \\ 1675 & 12.5 & 85 & 35 & 550 \\ 1700 & 15 & 75 & 30 & 525 \\ 1700 & 15 & 80 & 30 & 525\end{array}\right]$,

Make adjustments to satisfy all constraints. If new Tensile strength value is better than earlier, replace earlier Tensile strength with new one. Evaluate new population. 
ISSN 2349-9368 (Online); EAPJMER/issn. 2349-9368/2016; Volume 4 Issue 2 (2018)

Fitness $=\left[\begin{array}{l}621.5125 \\ 632.6088 \\ 606.4725 \\ 635.3638 \\ 632.6088\end{array}\right]$

Step 7. Find new particle best $\left(\mathrm{P}_{\text {best }}\right)$ and new global best $\left(\mathrm{G}_{\text {best }}\right)$ for new population.

Step 8. Update particle best and global best. If new particle is better than particle best, replace particle best with new particle. Find the best particle of new population. If it is better than $\mathrm{G}_{\text {best, }}$ replace $\mathrm{G}_{\text {best }}$ with best particle of new population.

Updated $P_{\text {best }}=\left[\begin{array}{lllll}1675 & 15 & 80 & 40 & 525 \\ 1700 & 15 & 80 & 30 & 525 \\ 1700 & 15 & 80 & 30 & 525 \\ 1700 & 15 & 75 & 30 & 525 \\ 1700 & 15 & 80 & 30 & 525\end{array}\right]$,

Updated Fitness $=\left[\begin{array}{l}621.5125 \\ 632.6088 \\ 632.6088 \\ 635.3638 \\ 632.6088\end{array}\right]$

Updated global best = $\left[\begin{array}{lllll}1700 & 15 & 75 & 30 & 525\end{array}\right]$,

Maximum tensile strength $=635.36 \mathrm{~N} / \mathrm{mm}^{2}$, Hardness Number value $=104.38$, Energy consumption $/$ Ton $=366.12 \mathrm{Kw}-\mathrm{H}$.

Step 9. Assign new velocity to old velocity.
Step 10. If termination condition is satisfied go to

Step 11. Otherwise go to step 5.

Step 12. Finalize the maximum tensile strength.

\section{RESULTS}

(Ref Figure-1) shows graph of Tensile strength versus number of iterations, it was observed that Tensile strength increases in the initial stage, reaches maximum and remains constant for the remaining iterations. In similar way as shown in fig.1, number of iterations is carried out and the best possible parameter setting level was obtained. The algorithm converges at Furnace temperature of $1700^{\circ} \mathrm{C}$, Sponge steel addition of $15 \%$, Scrap steel composition of $75 \%$, TDS number of water used at 35 and Quenching temperature of steel was at $500^{\circ} \mathrm{C}$. The output responses obtained by PSO algorithm are shown as below.

$\left[\begin{array}{lllll}1700 & 15 & 75 & 35 & 500\end{array}\right]$ as input parameters with output as:

Maximum tensile strength $=636.8550$

$\mathrm{N} / \mathrm{mm}^{2}$

Hardness Number $=105.1055$

Energy Consumption $=367 \mathrm{kWh}$. 
ISSN 2349-9368 (Online); EAPJMER/issn. 2349-9368/2016; Volume 4 Issue 2 (2018)

\section{EXPERIMENTATION}

The parameter setting $\left[\begin{array}{llll}1700 & 15 & 75 & 35\end{array}\right.$ 500] obtained by applying Particle Swarm Optimization algorithm is considered for experimentation. The optimized input parameters obtained were set and experiment was conducted for a steel rod of $16 \mathrm{~mm}$ diameter. A sample from the above lot is picked and tested for Tensile strength, Hardness number value and Energy consumption rate. The experimental results obtained are as shown below:

Maximum Tensile strength $=652.382$ $\mathrm{N} / \mathrm{mm} 2$

Hardness Number value $=105.89$

Energy Consumption $/$ Ton of steel $=361.372$ kWh.

The comparison of output values by PSO algorithm and experiment are shown in Table 2 below.

(Ref Figure 2) below shows graph for the comparison of algorithm values with experimental values for tensile strength, hardness number and energy consumption / ton of steel.

\section{CONCLUSION}

Quality of steel like its tensile strength and hardness number value play an important role in any civil structures. Optimization of process parameters to manufacture steel from secondary steel manufacturing is challenging task. Particle swarm optimization algorithm was applied to experimental results obtained from secondary steel manufacturing process, with an aim to increase tensile strength along with hardness number value and to decrease energy consumption rate. Regression equation obtained by response surface methodology was solved by the above stated technique and optimum input parameter levels were identified with corresponding output responses. The optimum input parameter levels obtained by particle swam optimization were analyzed by conducting experiment in a secondary steel recycling industry. The output responses for Tensile strength and Energy consumption rate/ton of steel show significant improvement, where as Hardness number value remains nearly same. The limitation of the work is only 16 $\mathrm{mm}$ rod is considered for experimentation and the results are valid for the same, where as there are steel rods of $5 \mathrm{~mm}, 8 \mathrm{~mm}, 10$ $\mathrm{mm}, 20 \mathrm{~mm}$ etc., also needs to be investigated. By using these results the mechanical properties definitely increases makes structures safer. 
ISSN 2349-9368 (Online); EAPJMER/issn. 2349-9368/2016; Volume 4 Issue 2 (2018)

\section{REFERENCES}

[1] A.R. Khoeia, I. Masters, D.T. Gethin

(2002), "Design optimization of steel recycling

processes using Taguchi technique", Journal of Materials Processing Technology, 127:

96-106.

[2] Anil Gupta, Hari Singh, Aman Aggarwal (2011), “Taguchi-fuzzy multi output

Optimization (MOO) in high speed CNC turning of AISI P-20 tool steel", Expert

Systems with Applications 38: 6822 6828.

[3] Melanie Haupt, Carl Vadenbo and Christoph Zeltner (2016), "Influence of input-scrap

Quality on the environmental impact of secondary steel production", Journal of Industrial

Ecology, version of record online.

[4] Mingyue Feng, Xianqing Yi (2008), "A grouping particle swarm optimization algorithm

for flexible job shop scheduling problem", IEEE Pacific-Asia workshop on
Computational Intelligence and Industrial Application, 333 - 336.

[5] V. K. Patel and R.V.Rao (2010)," Design optimization of shell-and-tube heat exchanger

using particle swarm optimization technique", Applied Thermal Engineering, 30: $1417-$

1425.

[6] Zhixiong Liu, (2007), "Investigation of particle swarm optimization for job shop

Scheduling problem”, Third International Conference on Natural Computation- (ICNC 2007).

[7] J. Kennedy and R.Eberhart (1995), "Particle swarm optimization", Proceedings of IEEE

International Conference on Neural Networks, 4: 1942-1948.

[8] Xiao Zheng, Zhenning Liu (2010), "The schedule control of engineering project based on

Particle swarm algorithm", Second International Conference on Communication Systems,

Networks and Application, 184-187. 
ISSN 2349-9368 (Online); EAPJMER/issn. 2349-9368/2016; Volume 4 Issue 2 (2018)

[9] Mingyue Feng, Xianqing Yi, Guohui

Li, Shaoxun Tang, He Jun (2008), “A Grouping

Particle Swarm Optimization Algorithm for Flexible Job Shop Scheduling Problem",

2008 IEEE Pacific-Asia Workshop on

Computational Intelligence and Industrial

Application, $332-336$.

[10] Hengyun Zhu1, Wenhua Ye, and Guangxia Bei (2009) "A Particle Swarm Optimization

for Integrated Process Planning and Scheduling”, IEEE, 1- 5

[11] Deng Linyi, LinYan (2007), “A

Particle Swarm Optimization for ResourceConstrained

Multi-Project Scheduling Problem", 2007 International Conference on Computational

Intelligence and Security, 1010 1014.

\section{LIST OF FIGURES}

Figure- 1
[12] Liyi Zhu, Jinghua Wu (2009), "Hybrid particle swarm optimization algorithm for flexible

task scheduling", 2009 Third International Conference on Genetic and Evolutionary

Computing, 603-606.

[14] Xiao Zhengi, Zhenning LiUi (2010), "The Schedule Control of Engineering Project

Based on Particle Swarm Algorithm", 2010 Second International Conference on

Communication Systems, Networks and Applications, $184-187$.

[15] Dian Palupi.R, Siti Mariyam.S, Siti Sophiyati.Y, "Particle Swarm Optimization:

Technique, System and challenges", International Journal of Computer Applications,

Vol.14-2011, 19-27. 
ISSN 2349-9368 (Online); EAPJMER/issn. 2349-9368/2016; Volume 4 Issue 2 (2018)

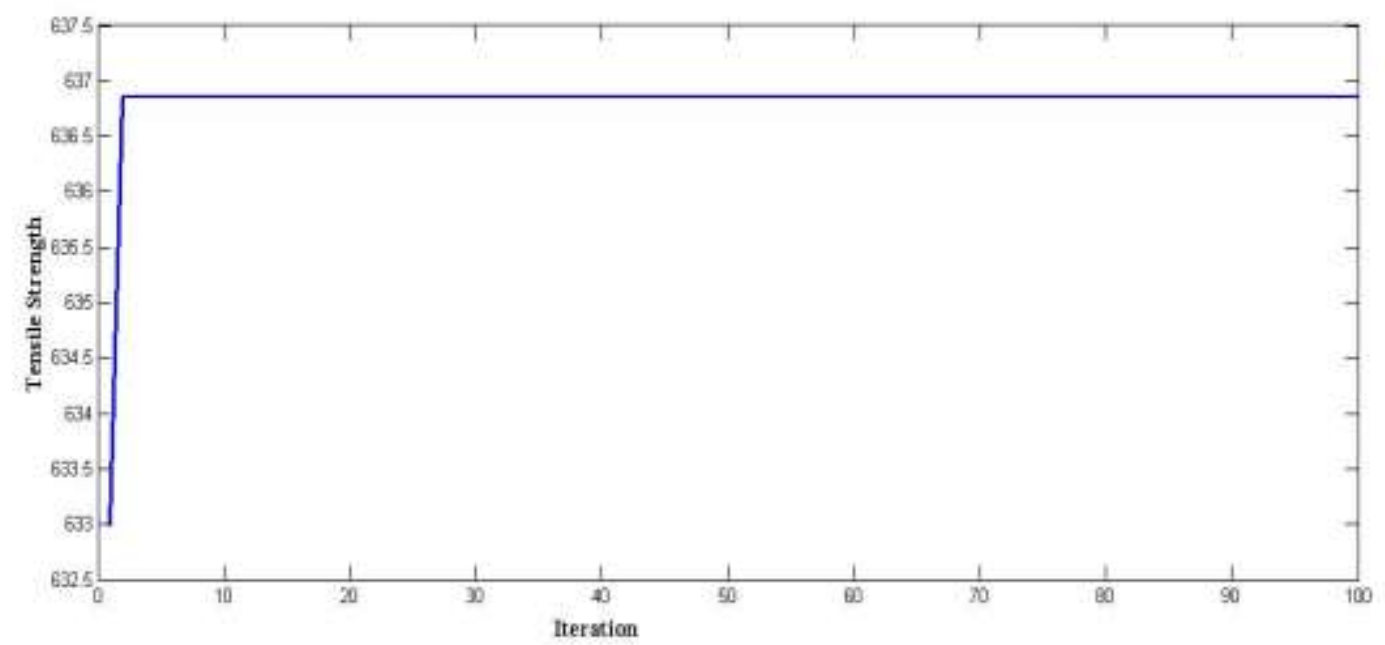

Fig.1. Graph showing Tensile strength variation with No. of Iterations

Figure- 2

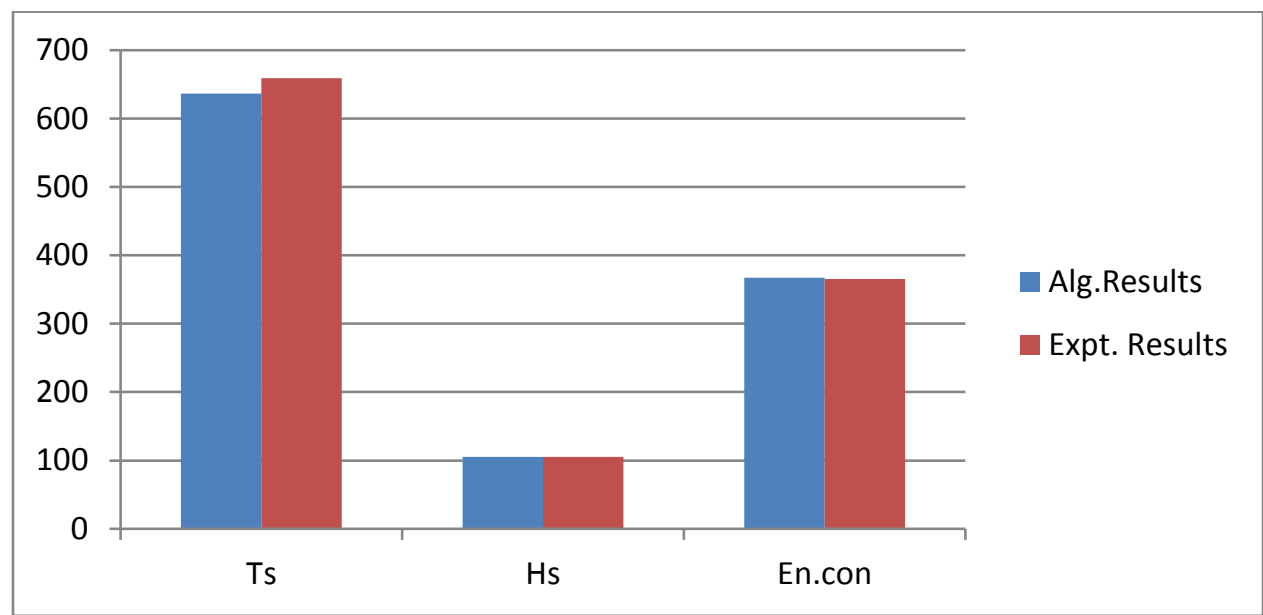

Fig.2. Graph showing Comparison of algorithm values with experimental values for output responses 


\section{LIST OF TABLES}

Table- 1

\begin{tabular}{|c|c|c|c|}
\hline Input Parameter & Level 1 & Level 2 & Level 3 \\
\hline $\mathrm{Ft}\left({ }^{\circ} \mathrm{C}\right)$ & 1650 & 1675 & 1700 \\
\hline $\mathrm{SS}(\%)$ & 10 & 12.5 & 15 \\
\hline $\mathrm{SCS}(\%)$ & 75 & 80 & 85 \\
\hline $\mathrm{TDS}(\mathrm{No})$. & 30 & 35 & 40 \\
\hline $\mathrm{Qw}\left({ }^{\circ} \mathrm{C}\right)$ & 500 & 525 & 550 \\
\hline
\end{tabular}

TABLE 1. Process parameters with their values at 3 levels

Table- 2

\begin{tabular}{|l|l|l|}
\hline Description & $\begin{array}{l}\text { Output values }- \text { PSO } \\
\text { Algorithm }\end{array}$ & $\begin{array}{l}\text { Output values- } \\
\text { experiment }\end{array}$ \\
\hline $\begin{array}{l}\text { Input Parameters obtained by } \\
\text { PSO Algorithm }[1700,15,75, \\
35,500]\end{array}$ & $\mathrm{Ts}=636.855 \mathrm{~N} / \mathrm{mm}^{2}$ & $\mathrm{Ts}=652.382 \mathrm{~N} / \mathrm{mm}^{2}$ \\
\cline { 2 - 3 } & $\mathrm{Hs}=105.11$ & $\mathrm{Hs}=105.89$ \\
\cline { 2 - 3 } & En.con. $=367.29 \mathrm{Kw}-\mathrm{H}$ & En.con. $=361.372 \mathrm{Kw}-\mathrm{H}$ \\
\hline
\end{tabular}

TABLE 2. Comparison of output values by PSO algorithm with experimental values 